\title{
Analysis of Four Years of Experience in a STEM Lecturer-training Program Based on Competencies
}

\author{
David Lopez, Antoni Perez-Poch, Ariadna Llorens Garcia, Mar Alier \\ david@ac.upc.edu, antoni.perez-poch@upc.edu, ariadna.1lorens@upc.edu, marc.alier@upc.edu \\ Institute of Education Sciences \\ Universitat Politècnica de Catalunya - Barcelona Tech \\ Barcelona, Spain
}

\begin{abstract}
This work in progress research-to-practice paper presents the analysis of the experience in the first four years of the lecturer training program developed at UPC-BarcelonaTech. The program, called Postgraduate Degree in University Teaching in STEM, started in September 2015. The program was designed based on the competencies a lecturer should possess with a special emphasis on developing a project to help lecturers to change the way they work on the teaching-learning process with their students. After four years of experience with the program, it is necessary to perform a critical analysis of the results, to find out what worked and what needs to be changed. This paper presents this analysis and the lessons learned in the process, as well as the changes required to increase the quality of the program as well as its attractiveness to lecturers.
\end{abstract}

\section{Keywords_-STEM education; Teacher training; professional competencies; soft skills; higher education}

\section{INTRODUCTION}

Good teaching depends to some extent on the competence of teachers. Despite this, pedagogical training of university lecturers is usually the result of a voluntary self-training process based on lecturers' experience and beliefs, rather than a mandatory program based on scientific evidence. These beliefs are built upon the lecturers' previous experience as students, the former students who attend their lecturers, the subject being taught, but mainly on their own idea about what good teaching means $[1,2,3]$.

Most universities offer training programs to their lecturers, but they are usually voluntary. The fact that such training is voluntary poses a problem: few lecturers enroll in the program because universities prioritize the scientific training and research capacity of teachers over the ability of training good professionals [4]. Thus, regarding their own career, some lecturers find this training as a "waste of time", because only published papers and grants obtained account for recruitment and promotion. In such situation, the main challenges when designing a training program is to make it useful and attractive for lecturers.

The Universitat Politècnica de Catalunya -Barcelona Tech is a technical one, only offering degrees in engineering, sciences and architecture. The university is divided into departments which belong to one of the following knowledge areas: Industrial Engineering, Information and Communication Technologies, Architecture, Management (always applied to engineering), Life Sciences (mainly bioengineering) and Civil Engineering. Our degrees are focused on engineering (e.g. we do not have a Chemistry Degree, but a Chemical Engineering Degree).

Given this context, the lecturers have the technical abilities required for teaching, but not necessarily the professional abilities required for good teaching. The lack of lecturer training is particularly problematic in engineering studies, which have one of the highest dropout rates in higher education.

At our university, lecturer training programs are undertaken by the Institute of Education Sciences, to which the authors of this work belong. The previous training program had a very low participation, so it was decided to completely change the philosophy of the program. First, and in order to make the new program more attractive it was converted to an official Postgraduate Degree, offered to our lecturers for free. The reason behind this change was that, while training courses does not account for promotion, being in possession of an official degree indeed does, thus resulting in something positive for the lecturers' career.

On the other hand, to make the new program more useful, some research was conducted to analyze the competencies required for STEM lecturers, resulting in six competencies: interpersonal; methodological; communicative; planning and management; teamwork; and innovation. Based on this research, a 15 ECTS (375 hours) postgraduate program was designed to help our lecturers to acquire these competencies. It was launched in September 2015. 
After four years of experience, it is necessary to perform a critical analysis of the results, to find out what worked and what needs to be changed. The results show that the program is highly valuated by the lecturers who followed it and the great impact it has had in their teaching activity. Nevertheless, the main drawback is that despite the number of lecturers who enroll in the program has increase, it is still very low.

The rest of the paper is organized as follows: Section II presents the previous work, describing the design process and the highlights of the program. Section III analyses the results obtained. Section IV discusses the lessons learned and the changes proposed. Finally, Section V presents the conclusions.

\section{PREVIOUS WORK}

Lecturer training in engineering has been the object of several studies (e.g. [5, 6]), but most of them focused on methods and tools for developing a high-quality teaching practice. There have been also a high number of studies about the so-called professional competencies (sometimes referred as soft skills) and their introduction into the curricula. These professional competencies include teamwork, effective communication, lifelong learning, sustainability and so on. Nevertheless, most of these studies have focused on the acquisition of these competencies among students with very few papers related with the competencies required for lecturers.

The Interuniversity Training Group for Teachers is a group of lecturers in charge of the lecturers' training programs in the eight public universities in Catalonia, a region in the north-east of Spain. This group conducted in 2011 a bibliographic study on the competencies that a university professor should possess. This study was followed by a focus group composed of 64 lecturers representing all fields of knowledge where the initial results were discussed. Once the validation was concluded, the following six competencies were identified: 1) Interpersonal; 2) Methodological; 3) Communicative, 4) Planning and Management; 5) Teamwork; and 6) Innovation. A more accurate definition of the six competencies can be found in [7].

Each competency was subdivided into a total of 49 indicators for the six competencies (the indicators list can be found in [8]). The results were endorsed by a survey among university lecturers asking about the importance they gave to each competence and indicator. The survey was validated using the judges' method with a total of 54 experts and sent to all the lecturers from the eight universities from whom a $15.43 \%$ of valid responses were received.

After analyzing the results of the survey, and a reflection process with lecturers and former students of the previous lecturertraining programs at our university, a Postgraduate Degree in University Teaching in Science, Technology, Engineering and Mathematics (STEM) was created and it started in September 2015 [9].

This Postgraduate Degree consist of 15 ECTS for student dedication, which are divided into:

- 6 mandatory credits consisting of 7 workshops, designed to reduce the number of contact hours and to promote personal work and the analysis on one's teaching activity. Six of these workshops are oriented to acquire the bases of each one of the six competencies, while the seventh was designed to plan the project to be developed (see below).

- 3 credits of complimentary training activities, which can be other workshops offered by the Institute, such as "Acting techniques for the teacher", "Podcasts", "Design Thinking" or "Flipped Classroom". All lecturers can choose which workshops he or she will attend according to their weaknesses and strengths.

- 6 credits of a final degree project which consists of analyzing a situation that occurs in their classes and of which they are dissatisfied. Then, they must propose and implement an educational innovation to tackle the problem and analyze the results of the proposed innovation. The project has a minimum duration of three semesters, with one dedicated to plan the innovation, analyze similar experiences and possible alternatives. In the following semesters, lecturers develop their innovation and analyze the results

The program has a minimum length of one year and a half, while a two-years period is recommended. Nevertheless, lecturers are encouraged to advance at their own pace, according to their interest and other occupations.

\section{RESULTS}

\section{A. Figures, surveys and developed projects}

The Postgraduate Degree in University Teaching in Science, Technology, Engineering and Mathematics (STEM) was launched in September 2015. A total of 114 participants (approximately 5\% of the total number of teachers at our university) initially enrolled for this program. Most participants come from the Civil Engineering department, Management and Computer Science.

Most participants were in the mid-stage of their careers (associate professors, 64\%), while the least represented category in the program corresponds to Professorships (7\%). Initial-stage teachers represent $29 \%$ of the participants, although this kind of training programs is mostly intended to serve lecturers who are at a beginner stage of their teaching careers.

In our University, composed of 2735 teachers (UPC internal report, 2018), 8,7\% of them are Professors, 41,4\% associate professors and $49,9 \%$ are assistant professors, lecturers in the initial stage of their career, or partial-time academic staff. Regarding knowledge areas (January 2020), 21,3\% belong to Industrial Engineering, 20,3\% belong to ICT (Information and Communications Technology), 19,8\% to Sciences, 18,7\% to Architecture, 6,5\% to Management, 5,7\% to Life Sciences and 7,7\% 
to Civil Engineering. Looking these numbers, one can observe that in our Program Professors are slightly underrepresented and initial-stage teachers clearly underrepresented. This is due to the fact that partial-time teachers do have a professional career outside the university; while most of the assistant professors are lectures usually have research requirements to achieve tenure that leave them less time for attending this type of training programs. Some of the knowledge areas are overrepresented in the program such as Management (usually linked to Engineering and Applied Management topics) and Civil Engineering which is due to the fact that there exists a tradition and interest groups in their departments on innovation and teaching topics.

Among those enrolled in the program, a group of 25 are already working on their final project, while 7 more will start this semester. The first graduation group of 17 teachers finished their Degrees in June, 2017, with a defense of their final project before a panel of experts in education. A group of 9 more teachers finished their degrees in June, 2018, 6 more in June 2019; and 14 lecturers are expected to complete their degrees during this academic year 2019-20. As an example, some titles of these final projects are: "The use of Kahoot as a motivational tool in a Master Program", "Just-in-time teaching improves student engagement among students at risk of failure in a Computer Science Fundamentals course", "CampusLabs at work in innovation campuses", "Developing the professional competence "Autonomous Learning' in the Graphical Expression subject", "Analysis of the impact of gamification in a Moodle-based subject" and "Flipped Classroom as a methodology for improving students' learning". Each academic course, an external evaluation board chose the Best Project within its promotion. In a final Open Day of the Program, its author is publicly recognized and awarded with a grant which is intended to publish her or his work in a relevant journal or in a renowned congress of Education.

Table 1 shows a comparison of the STEM program with the previous programs offered at our university. The PROFI program focused on the initial training of new teachers. Despite that 197 teachers certified during the 13 years of the program (more than 15 per year) the program was in decline because over the years the number of enrolled teachers decreased. That was probably due to the fact that very few teachers were hired at our university during the crisis years, a trend that unfortunately has not changed at present.

TABLE I. COMPARISON BETWEEN STEM AND PREVIOUS PROGRAMS.

\begin{tabular}{|c|c|c|c|}
\hline Program & PROFI & PIDU & STEM \\
\hline Years & $\begin{array}{c}1999-2012 \\
\text { (13 years) }\end{array}$ & $\begin{array}{c}2012-2015 \\
(3 \\
\text { years })\end{array}$ & $\begin{array}{c}2015-\ldots \\
\text { (4 years so far })\end{array}$ \\
\hline Training hours & 130 & 150 & 375 \\
\hline $\begin{array}{c}\text { Total } \\
\text { participants }\end{array}$ & 979 & 70 & 114 \\
\hline Certified & 197 & 7 & $\begin{array}{c}32 \\
(14 \text { more } \\
\text { expected by } \\
2020)\end{array}$ \\
\hline
\end{tabular}

The next program (PIDU, 2012-15) was oriented to teaching competences, with six 25-hours courses, one per competence. In terms of enrolled students, it showed the PROFI tendency to decline. Analyzing the teacher's comments the two main concerns of the program were: 1) it does not account for promotion (so we decided to offer a Postgraduate title) and 2) teachers want a follow up of their own application of the learned techniques at class (and the final project was the best way to assure this follow up).

Current figures show that 148 teachers are actively enrolled in the STEM program, with 25 in their final stage of developing their final project. Participants chose their pace in the program depending on their priorities in research, management or teaching duties.

Since its implementation, some indicators of attendance at our teacher-training program have improved (not only for this degree but the across the whole spectrum of training). For example, the Hours of Training/Teacher ratio per year has increased by $62 \%$ over the last academic year 2015/16 when compared with 2014/15. Furthermore, the number of teachers attending courses has increased by $64 \%$ in the last year in comparison with the lowest figure recorded in 2014/15.

Regarding STEM Students' satisfaction with their training, it is very high according to an anonymous poll conducted after every course. The general average of satisfaction in mandatory subjects is 4.3 (out of 5, Likert Scale). Attendants often express their difficulties for attending face-to-face training sessions at fixed hours. The same initial proportion of approximately two thirds of the students enrolled still holds for middle-stage career teachers (associate professor), with less than 5\% of Professorships and a remaining 30\% of initial-stage teaching career. Proportions are depicted in Figure 1. Lecturers enrolled in the program belong to a wide variety of departments and knowledge areas, which is certainly an enriching feature of this program. The most represented areas are Management, Architecture and Computer Science. 


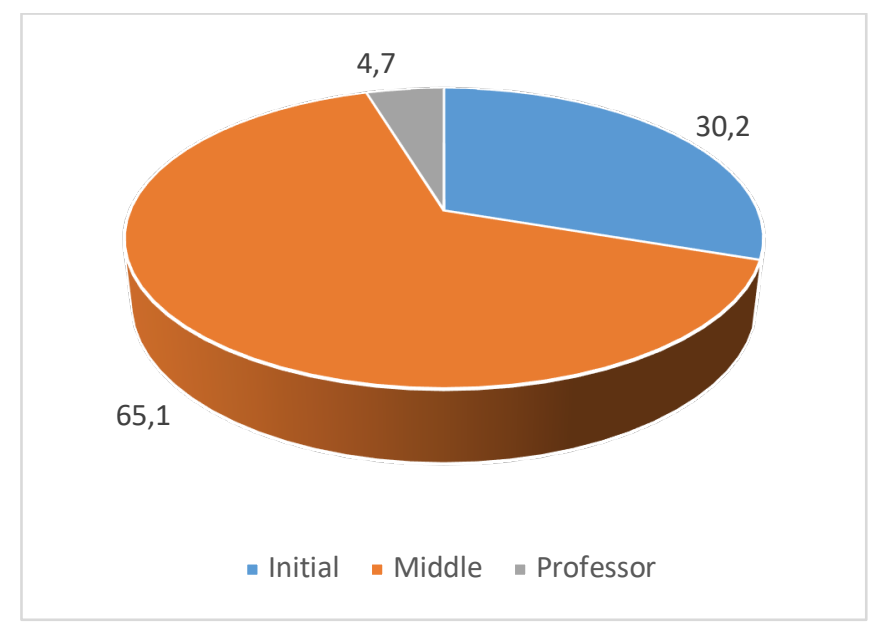

Fig. 1. Career stage of STEM participants (\%).

\section{B. The focus group}

A focus group was conducted in the Fall semester of the academic course 2019-2020 to discuss the results and to propose possible changes. The group was composed by six people (students, alumni, teachers and people in charge of the program), observing gender parity.

Different discussion points were raised to the focus group. The first one was about how to attract more lecturers to the Postgraduate Degree. There has been a significant increase in enrolment the new courses offered by the institute (a 64\% increase in teachers enrolled in a course). Therefore, it seems that the problem is not in the lack of interest of lecturers in attending the courses, but rather in the postgraduate approach itself.

The participants indicated that the courses were very useful and that lecturers have applied many of the techniques learned in their own classes, but that they have sometimes found it difficult to move from the theories and methodologies learned to their own subject. An accompaniment of experts in the own fields of knowledge is missing. For example, one of the former graduate students, lecturer of fluid dynamics pointed:

"I needed an expert in education but who knew the problems inherent in teaching fluid dynamics to help me transfer the methodologies I was learning to my classes."

Among the points to improve in the Postgraduate Degree there was consensus in the problem that the seven compulsory courses had an important face-to-face part, and that given the disparity of the teachers' schedules, it was very difficult to attend these courses. The organization of these basic courses should be improved to facilitate our teachers to enroll and attend them.

It has been also pointed out that currently there are not courses oriented to philosophy, ethics or art, simply they are just oriented to education. In the opinion of the focus group, these types of courses are asked for by our teachers.

Finally, participants indicate the pressure that teachers have to publish and obtain grants, since they are the key points for promotion, while good teaching is practically not given any value. The postgraduate program must be changed to be more attractive from the point of view of the benefit it may have for the lecturers' career.

\section{DiSCUSSION}

According to the results and opinions received, the design of the degree based on competencies approach is very positive. The fact that it is an official Postgraduate Degree is positive because every official degree account for hiring and promotion. Therefore, and given that according to the regulations of our country an official postgraduate degree must have at least 15 ECTS, the duration is appropriate.

To make the program more attractive, and since the promotion in our university is based on published papers, it is necessary to promote the publication of the resulting innovation experiences conferences and magazines of high quality, so that they are more useful for lecturers' careers. Thus, it is necessary to implement a plan for accompanying lecturers in the design of innovations, their theoretical bases and the measurement of results in order to help them to publish their educational experiences.

To improve the attraction of the courses offered by the degree, the following ideas are proposed:

- Simplify the basic and compulsory courses so that they focus on the first two levels of Bloom's taxonomy (Remember and Understand) [10] and turn them into e-learning courses, with readings, videos and the preparation of an essay oriented to a critical reflection of their own activity as a teacher regarding that competence. Thus, it will be easier for more lecturers to follow them.

- Increase the number of optional courses, more oriented to the higher levels of Bloom's taxonomy. Focus them on issues of technology use (creation of educational videos, podcasts, tools for e-learning and blended-learning).

- Encourage the use of a teaching portfolio as a tool to assess the progress of students in the degree. 
- Encourage the use of coaching and peer-to-peer techniques to help lecturers apply theories, methodologies and tools in their own environment.

Therefore, the courses offered within the postgraduate must be redesigned. They should be simplified and reduced the compulsory ones until they have the minimum required bases and turn them into distant learning courses. The course catalogue should be expanded and diversified, with courses focused on the pedagogical use of new tools. Furthermore, courses about humanities, art, ethics, and so they should be included (it is proposed to change the title of the postgraduate course in STEM education to STEAM education, where the "A" stands for Arts, as understood as humanities). All courses offered should define how much time they dedicate to each of the six competencies. For example, a podcast creation course would offer training not only for the communicative competence, but also for planning and management, for innovation and for methodology. How much each course helps to develop each competence would appear as an evidence in the teaching portfolio of each student. Participation in conferences or coaching activities would be included as well, as further evidence of the development of these competencies.

Hence, a student would complete the courses' part of the Postgraduate Degree when the evidence from their portfolio indicates that he or she has reached a certain level in all six competencies.

Regarding the final innovation project, it is proposed that it can be replaced by a quality publication on teaching innovation, so that the student can choose between presenting a report of their work or a published paper with the results.

Although the program is mostly appropriate for initial-stage teachers, as stated in the results, this category is clearly underrepresented in our training program. However the efforts that we propose herein and may be put into place, there is a general trend in worldwide universities, linked to the pressure to publish research in high-impact journals, which makes it difficult for non-tenured university teachers to spend time and efforts in programs like this one. Also, a particular lack of recruitment of teachers due to insufficient resources placement in countries like Spain makes the number of potential initial-stage teachers very scarce. Hiring is often based in partial-time teachers who already have professional duties outside university and may not be available for further pedagogical training. A better investment human-resources policy, and a better recognition for teacher training programs like the one analyzed will certainly result in an improvement of these figures. Furthermore, we recommend that a minimum initial-based pedagogical training should be mandatory into the duties of the academic staff.

\section{CONCLUSiOnS}

This work analyses four years of a competency-based lecturer training post graduated program. Despite most universities having lecturer training programs, there are very few of them that are: a) oriented to lecturers' competencies, b) with such an amount of time dedicated to it, and c) with a mandatory project that must be implemented in class as part of their teaching training.

Results show that the program is highly valued by the lecturers who attended it, and that it has had a great impact in their teaching activity. Nevertheless, after four years a critical assessment of the program is needed. With this work-in-progress the authors want to share the problems they faced, and the lessons learned after four years of experience to help other universities wanted to develop similar programs.

As future work, it is planned to implement the changes proposed in the Discussion Section and study if they have an impact on the number of lecturers enrolled into the Postgraduate Degree in University Teaching in STEAM.

\section{ACKNOWLEDGMENT}

The authors want to thank all teachers and students of the Postgraduate Degree for their effort and valuable feedback on the program, and in particular those who volunteered for the focus group. They also want to thank the technical staff of the Institute of Education Sciences for the great work done.

\section{REFERENCES}

[1] Kagan, Dona M. "Implication of research on teacher belief." Educational psychologist 27, no. 1 (1992): 65-90. https://doi.org/10.1207/s15326985ep2701 6

[2] Prawat, Richard S. "Teachers' beliefs about teaching and learning: A constructivist perspective." American journal of education 100, no. 3 (1992): $354-$ 395. https://doi.org/10.1086/444021

[3] Posner, George J., Kenneth A. Strike, Peter W. Hewson, and William A. Gertzog. "Accommodation of a scientific conception: Toward a theory of conceptual change." Science education 66, no. 2 (1982): 211-227. https://doi.org/10.1002/sce.3730660207

[4] Shulman, Lee S. "Those who understand: Knowledge growth in teaching." Educational researcher 15, no. 2 (1986): 4-14. https://doi.org/10.3102/0013189X015002004

[5] Fink, L. Dee, Susan Ambrose, and Daniel Wheeler. "Becoming a professional engineering educator: A new role for a new era." Journal of Engineering Education 94, no. 1 (2005): 185-194. https://doi.org/10.1002/j.2168-9830.2005.tb00837.x

[6] Shuman, Larry J., Mary Besterfield-Sacre, and Jack McGourty. "The ABET "professional skills"-Can they be taught? Can they be assessed?." Journal of engineering education 94, no. 1 (2005): 41-55. https://doi.org/10.1002/i.2168-9830.2005.tb00828.x

[7] Lopez, David, A. Adam, María J. Delgado., Enric Mayol, and Marc Alier. "A design pattern for skills based lecturer training programs." In Proceedings of the Research in Engineering Education Symposium 2015: Dublin, Ireland, pp. 1-9. 2015. Available on line: http://hdl.handle.net/2117/86121

[8] Lopez, David and Antoni Perez-Poch. "Detecting which teaching competences should be reinforced in an engineering lecturer training program." In SEFI 2016 Annual Conference: full papers, pp. 1-11. European Society for Engineering Education (SEFI), 2016. Available on line: https://core.ac.uk/reader/81572105 
[9] Lopez, David and Antoni Perez-Poch. "Design of a STEM lecturer-training programme based on competencies." The International journal of engineering education 34, no. 5 (2018): 1495-1503. Available on line: https://www.ijee.ie/latestissues/Vol34-5/07 ijee3659.pdf

[10] Krathwohl, David R., and Lorin W. Anderson. "A taxonomy for learning, teaching, and assessing: A revision of Bloom's taxonomy of educational objectives". Longman, 2009. 